\title{
Early identification of first-year students at risk of dropping out of high-school entry medical school: the usefulness of teachers' ratings of class participation
}

\author{
Alexandra M. Araújo ${ }^{1}$. Carlos Leite ${ }^{2}$ Patrício Costa ${ }^{3,4} \cdot$ Manuel João Costa ${ }^{3,4}$
}

Received: 25 April 2018 / Accepted: 3 November 2018

(c) Springer Nature B.V. 2018

\begin{abstract}
Dropping out from undergraduate medical education is costly for students, medical schools, and society in general. Therefore, the early identification of potential dropout students is important. The contribution of personal features to dropout rates has merited exploration. However, there is a paucity of research on aspects of student experience that may lead to dropping out. In this study, underpinned by theoretical models of student commitment, involvement, and engagement, we explored the hypothesis of using inferior participation as an indicator of a higher probability of dropping out in year 1. Class participation was calculated as an aggregate score based on teachers' daily observations in class. The study used a longitudinal dataset of six cohorts of high-school entry students $(\mathrm{N}=709,67 \%$ females $)$ in one medical school with an annual intake of 120 students. The findings confirmed the initial hypothesis and showed that lower scores of class participation in year 1 added predictive ability to pre-entry characteristics (Pseudo- $R^{2}$ raised from 0.22 to 0.28 ). Even though the inclusion of course failure in year 1 resulted in higher explanatory power than participation in class (Pseudo- $R^{2}$ raised from 0.28 to 0.63 ), ratings of class participation may be advantageous to anticipate dropout identification, as those can be collected prior to course failure. The implications for practice are that teachers' ratings of class participation can play a role in indicating medical students who may eventually drop out. We conclude that the scores of class participation can contribute to flagging systems for the early detection of student dropouts.
\end{abstract}

Keywords Dropout $\cdot$ Medical education $\cdot$ First year $\cdot$ Engagement $\cdot$ Class participation

Alexandra M. Araújo

amaraujo@upt.pt

1 INPP, Portucalense Institute for Human Development, Department of Psychology and Education, Portucalense University, Rua Dr. António Bernardino de Almeida, 541, 4200-072 Porto, Portugal

2 School of Economics and Management, University of Minho, Braga, Portugal

3 Life and Health Sciences Research Institute (ICVS), School of Medicine, University of Minho, Braga, Portugal

4 ICVS/3B's - PT Government Associate Laboratory, Braga/Guimarães, Portugal 
Some outstanding pre-university students may become "strugglers" or "at risk" in medical school, showing issues with performance (academic, clinical, or professional), social relations, or academic commitment (Yates and James 2006; O'Brien et al. 2007; Frellsen et al. 2008; Garrud and Yates 2012; Sandars et al. 2014). Struggling might also be indicative of future lapses in professional behavior as a doctor, as suggested by retrospective studies in the USA and the UK (Papadakis et al. 2004; Yates and James 2010). Signs of struggling identified by O'Neill et al. (2016) include issues with participation (e.g. passivity, lack of initiative, lack of active participation in the classroom), commitment (e.g. lack of motivation, lack of interest), academic involvement (e.g. difficulties with learning, lack of study skills), social interaction (e.g. problems with integration in the group, lack of social contact), and distress (e.g. visible insecurity). Strugglers may eventually drop out from undergraduate medicine or transfer to another medical school (Arulampalam et al. 2004, 2007; Ward et al. 2004; Yates and James 2006; Yates 2011; Mørcke et al. 2012).

International medical school dropout rates are generally under-documented. Prior research has described approximate figures of 3-5\% (Arulampalam et al. 2007), 4\% (Yates 2012) and 14\% in the UK (Simpson and Budd 1996), 6\% in Ireland (Maher et al. 2013), 15\% in Australia (Ward et al. 2004), 3-20\% in The Netherlands (Urlings-Strop et al. 2009), and as high as $27 \%$ in one Danish school (Mørcke et al. 2012). Although the prevalence of medical student dropouts is comparatively lower in other undergraduate programs, averaging 11.1\% (O'Neill et al. 2011), dropping out has particularly severe and long-lasting consequences for the institutions and the individual. Institutionally, the public and private investment do not result in the intended return (Jones and Korn 1997). Individually, dropping out represents financial losses and psychological distress (Dyrbye et al. 2006; Compton et al. 2008). Departure from medical school may impact strongly on student' self-confidence, as the associated frustration with the failure to follow the calling for medical practice may impair students' career development (Duffy et al. 2011; Liu et al. 2015). Therefore, understanding the causes and processes of dropping out is important at the individual and institutional levels.

The causes of dropout are not totally clarified, but they are clearly multifactorial. Some individual variables, such as personality (low neuroticism and high conscientiousness) and future career and lifestyle expectations may contribute to discourage dropout (Simpson and Budd 1996; Tyssen et al. 2007). In contrast, sociodemographic characteristics, such as sex, age, social class, and parents' education have not been consistently associated with dropping out (O'Neill et al. 2011). In what concerns pre-entry academic performance, individuals with lower entry qualifications have higher risks of dropping out (Yates and James 2006; O'Neill et al. 2011). As to academic achievement in medical school, higher dropout rates have been associated with failing year 1 courses (Hojat et al. 1997; Yates 2012) and repeating exams and study years (Maher et al. 2013). Since most dropouts are observed in the first year (Simpson and Budd 1996; Yates 2012; Maher et al. 2013), early academic records might be useful to flag students with subsequent academic difficulties (Yates and James 2007; Yates 2011, 2012). Regarding other aspects of the experience in medical school, performance in formative tests, face-toface interactions, and group discussions with faculty and peers have a positive impact on academic satisfaction and achievement, as well as course completion (Bösner et al. 2015; Goldberg et al. 2015; Lameris et al. 2015). Finally, students with difficulties with integration, including experiences of loneliness, despair, anxiety, depression, and difficulties in coping with the school workload have more self-reported thoughts of dropping out and are more likely to abandon medical school (Dyrbye et al. 2010; Yates 2012; Maher et al. 2013). 
Despite relatively extensive literature regarding the characterization of dropouts, there is still an insufficient understanding of which variables could be used as dropout predictors or their interrelations. Furthermore, a theoretical model is missing about the process for undergraduate medical student dropout. Theoretical models from the wider literature on the persistence of college students, namely Tinto's interactionalist theory (Tinto 1993) and Astin's involvement model (Astin 1984), may offer a lens to guide the untangling of complexity in the process of dropping out of medical education. Tinto's (1993) theory is concerned with students' persistence in higher education — the opposite of dropping outand describes the process of voluntary student departure as longitudinal. Tinto's model emphasizes the influence of student entry characteristics-previous education and sociodemographic background - on initial intentions, levels of commitment, and academic aspirations, which then influence academic and social integration, which will, in turn, shape decisions to persist or to drop out. Astin's involvement model (1984) emphasizes the physical and emotional energy students devote to a particular program to explain institutional commitment and academic success. According to this model, academic success, including students' learning and personal development, is directly associated with the quality and quantity of involvement, conceptualized not only as what the individual thinks or feels, but what he or she does and how he or she behaves. The model includes three particularly relevant aspects of involvement in college: interactions with faculty, with academics, and with peer groups. Both Tinto and Astin's models agree that student-related variables (preentry characteristics and educational-related experiences) are translated into commitment and involvement, influencing student persistence. Abundant research with college students supports such models, showing that the quantity and quality of engagement in educationally purposeful academic and social experiences, particularly in the first year, are important for persistence in higher education (Carini et al. 2006; Compton et al. 2008; Krause and Coates 2008; Kahu 2013). Probabilities of persistence are positively associated with study time, peer interactions to deliver assignments, interactions with faculty, and class engagement behaviors (Kuh 2003; Robbins et al. 2004; Kuh et al. 2008; Svanum and Bigatti 2009).

Participation in class activities is potentially an indicator of the quality of medical students' involvement (Astin 1984) and engagement (Kuh 2003; Robbins et al. 2004; Carini et al. 2006; Kuh et al. 2008; Kahu 2013; Tinto 2012). Therefore, teacher or peer ratings of class participation may contribute to predict dropouts, adding to predictors such as gender, academic preparation, or grade point averages (GPAs). Such ratings would provide a longitudinal indicator of the process of dropping out, potentially anticipating remediation and prevention interventions. Interestingly, tutors are to some extent able to predict the examination performance of students in their tutor groups, although the association between tutors' predictions and subsequent academic performance and dropout is weak to moderate (Kaufman and Hansell 1997; Adam et al. 2012; Wijnia et al. 2014, 2016). In addition, tutors seem to be better at predicting completion of the course or year than at identifying potential failure or dropout (Wijnia et al. 2014, 2016), as there seems to be an overestimation of students' skills, especially for those in the lowest quartile (Whitfield and Xie 2002). The study by O'Neill et al. (2016) with medical students showed that tutor daily informal observations could accurately predict student failure, albeit tutors tended to under-detect those who were at risk of failing on the following exam or drop out of the program. Such observations provided incremental validity for the prediction of strugglers when controlling for grades in previous exams. In sum, prior research suggests the usefulness of tutors' ratings to anticipate struggling and dropping out of medical education. However, such research has been conducted mainly in PBL settings and small group classes, which allow 
frequent tutor/student group contacts. Further research is needed in other types of learning environments, including large classes in non-PBL settings.

This study follows the suggestion by O'Neill et al. (2016) to examine "a combination of teachers' independent informal judgments of specific in-class behavior (participation, commitment, academic performance, social interactions, distress) in addition to early performance testing" (p. 1076). We examined the relevance of including a mark computed from quantitative teachers' ratings of class participation as a predictor variable of dropouts. The hypothesis was that higher class participation ratings can be seen as a proxy for higher commitment (Tinto 1993), academic involvement (Astin 1984), and engagement (Hu and Kuh 2002; Kuh et al. 2008; Kahu 2013), and would be therefore negatively associated with dropout (and positively associated with students' persistence). Participating in class has several benefits, including higher levels of motivation and academic performance, as well as the development of communication and critical thinking skills (Rocca 2010). In the current study, we used participation ratings of six consecutive cohorts to examine the incremental power of class participation to predict medical school dropout, while also considering background characteristics and academic achievement during medical school. Our main research question was: will the inclusion of teachers' ratings of class participation improve the prediction of year 1 medical student dropouts over background variables and academic performance? The expectations were that our findings could clarify whether such ratings could anticipate the identification of potential dropouts and contribute to the development of educational interventions that promote persistence.

\section{Methods}

\section{Context}

This study was developed at Minho medical school in Portugal. In this school, the undergraduate curriculum is horizontally and vertically integrated. A systems-based, case-based approach is used for basic sciences, with early clinical contact, increasing at the end of year 3. Undergraduate-entry and graduate-entry applicants enter a 6-year (120 students) and a 4-year long track (18 students), respectively, and share the same clinical training. The assessment program requires students to demonstrate satisfactory knowledge, abilities, and professional standards of behavior throughout the whole program.

The admission criteria for undergraduate-entry applicants is the ranking on a national list of admission grade-point averages, determined by academic performance in secondary education and results in national exams. Applicants compete for places indicating, by order of preference, six combinations of institution and study program. Those who are not placed in their first preference may be admitted to the second-best alternatives. Therefore, top academic performers in secondary education have a better chance of being admitted to their first preference and students who are not placed in their first preference might be dissatisfied with the outcome of their application (Fonseca et al. 2014). There are additional alternative positive discrimination admission regimes for a small percentage of places.

\section{Participants}

The participants were not approached directly to develop this study. Data were collected from the University of Minho Medical School's longitudinal research database which holds 
identified student records including personal, sociodemographic, and academic information. The data refer to all students with complete datasets, who had made a first registration in Minho's medical degree between 2007 and 2013.

\section{Operationalization of the dropout variable}

This study defined a dropout as a student who did not complete the academic program, due to voluntary resignation or transfer to another medical school or degree in higher education. Dropout, the dependent variable in the current study, was dummy coded, where $0=$ non-dropout and $1=$ year 1 dropout from medical school.

\section{Data collection}

Data collected at the beginning of year 1 included demographic and personal characteristics, pre-university academic performance, family background, and the admission regime. Academic performance was collected in year 1 . The teachers' ratings of class participation were provided by administrative services.

\section{Predictor variables}

The predictor variables (Table 1) were selected from the longitudinal research database and were referred to in college student retention models presented by Tinto (1993) and Astin (1984).

\section{Entry characteristics}

The entry characteristics included demographics—sex, age, and place of residence-and admission data-the admission GPA, student preference for the Minho's undergraduate medical degree at application, institutional commitment, and declared need of financial aid.

\section{Academic experience}

The academic experience variables included both the ratio of failed courses per total of courses students were enrolled in and teachers' ratings of class participation.

\section{Teachers' ratings of class participation}

As part of the assessment program in the initial 3 years of the medical degree, teachers at Minho's medical school are required to assign a quantitative mark of individual student participation during classes. The average mark of class participation accounts for $10 \%$ of the final mark in all courses, after it is multiplied by 4 to obtain a grade ranging from 0 to 20 , as determined by national regulations. Marking is ideally performed upon class conclusion, for as many students as possible. The participation marks range from 1 (low participation) to 5 (high participation) and are assigned using a customized online platform displaying students' names and photos, with restrict access for teachers. Non-attendance is marked with 0 . Positive behaviors include observable active participation in class, such as asking or answering questions, and making active contributions to class or group 


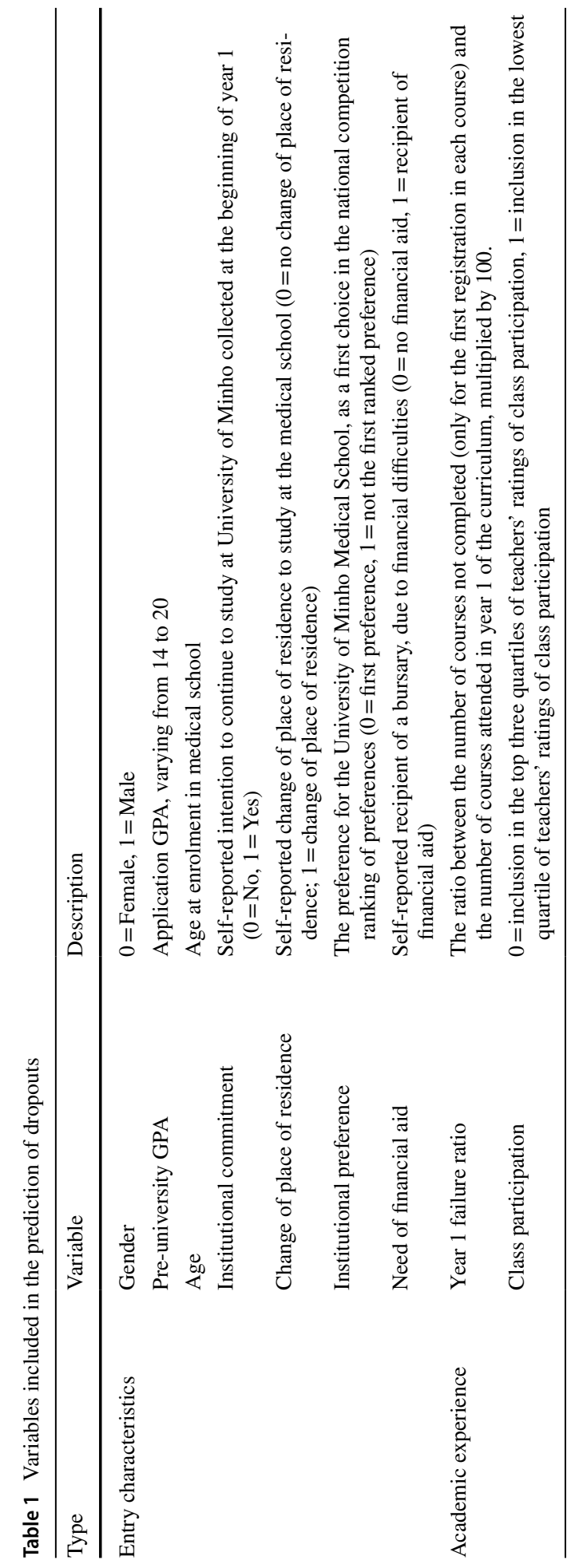


discussions. The marking process and criteria for marking are identical across courses and presented to students at the beginning of each course. There are roughly 20 classes every week, which are all opportunities for teachers to evaluate and register participation. Course coordinators monitor all marks of all teachers in real time and work with teachers to ensure that every student is evaluated over time.

For this study, the variable teachers' ratings of class participation corresponded to the mean of all scores provided by all the teachers of the three large first-year courses, which represent $88 \%$ of the ECTS credits. Since the goal was to study the potential of low class participation to predict dropouts, teachers' ratings of class participation was dichotomized: $0=$ students in the top three quartiles of teachers' ratings of class participation, $1=$ students in the lowest quartile of teachers' ratings of class participation.

\section{Modeling and statistical analysis}

To explore how the predictor variables influenced dropping out, logit regression models were conducted using Stata 14, using different sets of predictor variables. The baseline model (Model A) was developed to evaluate the predictive ability of variables available at the beginning of medical school, and included exclusively the student entry characteristics: gender, pre-university GPA, age, change of place of residence, institutional commitment, institutional preference stated in the national competition, and benefit of financial aid. To evaluate the incremental power of the academic experience in medical school for the prediction of dropouts, two additional models were developed adding different variables to the baseline model: the teachers' ratings of class participation (Model B), and a combination of teachers' ratings of class participation and the failure ratio in year 1 (Model C). We conducted Wald tests on the marginal effects of each variable to estimate their significance and magnitude as predictors of dropout. To aid the interpretation of the models, we calculated measures of classification (hit rate, specificity, sensitivity, improvement over chance index, and ROC curves).

\section{Ethical approval}

The development of the longitudinal database and research supported on these data is approved by the Portuguese Commission for Data Protection (CNPD: 10432/2011). Students gave informed consent for the use of their information for administrative and research purposes at the time of collection. Confidentiality and anonymity were guaranteed.

\section{Results}

\section{Descriptive statistics}

Within a population of 709 students with full records (67\% females; Mean age in year $1=19.39$ years, $S D=2.97)$, 43 students met the dropout criteria $(6.1 \%)$. As for the remaining 666 students who did not drop out, 453 (69\%) were females, and ages ranged from 16 to 38 years $(M=19.34, S D=2.84)$. The number of dropouts was highest in year 1 , with 34 student dropouts (79.1\% of total dropouts). The additional dropouts were $4(9.3 \%)$ in year $2,2(4.7 \%)$ in year $3,1(2.3 \%)$ in year $4,1(2.3 \%)$ in year 5 , and $1(2.3 \%)$ in year 6 . We focused the current study on students who dropped out in year 1 , who were predominantly 
Table 2 Dropout rates in the six cohorts of medical students (2007-2013; N=34)

\begin{tabular}{lcc}
\hline & No. dropouts $(\%)$ & $\begin{array}{l}\text { \% Dropouts } \\
\text { per cohort }\end{array}$ \\
\hline $2007 / 2008$ & $4(11.8)$ & 4.6 \\
$2008 / 2009$ & $3(8.8)$ & 2.6 \\
$2009 / 2010$ & $7(20.6)$ & 6.2 \\
$2010 / 2011$ & $2(5.9)$ & 1.7 \\
$2011 / 2012$ & $15(44.1)$ & 13.4 \\
$2012 / 2013$ & $3(8.8)$ & 2.9 \\
Total & $34(100)$ & 5.3 \\
\hline
\end{tabular}

\begin{tabular}{llllllll}
\hline & Min & Max & $M$ & $S D$ & Q1 & Q2 & Q3 \\
\hline IMD & 5 & 19 & 14.04 & 2.07 & 12 & 14 & 16 \\
MC & 6 & 19 & 13.30 & 1.80 & 12 & 13 & 14 \\
OSI & 10 & 18 & 14.55 & 1.13 & 14 & 15 & 15 \\
Total score & 8.45 & 18 & 13.91 & 1.34 & 13.09 & 13.87 & 14.70 \\
\hline
\end{tabular}

$I M D$ Introduction to the Medical Degree, $M C$ Molecules and Cells,

OSI Organ Systems I
Table 3 Teachers' ratings of class participation in year 1

females $(n=24,71 \%)$ and with ages ranging from 17 to 35 years (Mean age $=19.39$, $S D=4.04$ ). The 34 year 1 students who dropped out accounted for a dropout rate of $5.3 \%$ of all 647 students. Table 2 presents the distribution of dropouts per cohort, showing that most dropout students (37.21\%) were from the 2011/2012 cohort.

\section{Scores of teachers' ratings of class participation}

Table 3 presents teachers' ratings of class participation for the three courses that represent $88.3 \%$ of year 1 ECTS credits, on a 0 to 20 points scale, with values for the first, the second, and the third quartile. These courses occur sequentially, and no other courses are running simultaneously. Students had the lowest class participation if they had participation scores under 12 for "Introduction to the Medical Degree" (4 ECTS) and "Molecules and Cells" (24 ECTS), under 14 for "Organ Systems I" (25 ECTS), and under 13.09 for the total weighted arithmetic mean score.

As shown in Table 4, the participation scores of dropout students were significantly lower as compared to the participation of students who persisted, in all courses. This difference was highest for the "Molecules and Cells" course. The effect sizes for the group differences were medium to large, according to Cohen's (1988) benchmark guidelines.

\section{Predictors of dropouts}

Table 5 presents the results of the logit models for the prediction of dropouts. In the baseline model (model A), which only included admission characteristics as the predictors, higher probabilities of dropping out were associated with lower pre-university GPAs $(\mathrm{OR}=0.97, p<0.05)$, older ages $(\mathrm{OR}=1.24, p<0.001)$, a lower institutional commitment at the beginning of the first year $(\mathrm{OR}=0.25, p<0.001)$, a lower preference for the 
Table 4 Class participation differences between non-dropout and dropout students

\begin{tabular}{|c|c|c|c|c|c|c|c|c|}
\hline & \multicolumn{3}{|c|}{ Non-dropouts $(n=613)$} & \multicolumn{3}{|c|}{ Dropouts $(n=34)$} & \multirow[t]{2}{*}{$t(645)$} & \multirow[t]{2}{*}{ Cohen's $d$} \\
\hline & $M$ & $S D$ & $95 \% \mathrm{CI}$ & $M$ & $S D$ & $95 \% \mathrm{CI}$ & & \\
\hline IMD & 14.12 & 2.05 & {$[13.96,14.29]$} & 12.48 & 1.75 & {$[14.29,13.11]$} & $4.57 *$ & 0.86 \\
\hline MC & 13.39 & 1.77 & {$[13.24,11.20]$} & 11.76 & 1.57 & {$[11.20,12.31]$} & $5.26^{*}$ & 0.97 \\
\hline OSI & 14.58 & 1.10 & {$[14.49,14.67]$} & 13.69 & 1.44 & {$[13.11,14.27]$} & $4.51 *$ & 0.69 \\
\hline Total score & 13.99 & 1.30 & {$[13.88,14.09]$} & 12.60 & 1.34 & {$[13.81,14.02]$} & $6.06^{*}$ & 1.05 \\
\hline
\end{tabular}

IMD Introduction to the Medical Degree, MC Molecules and Cells, OSI Organ Systems I; * $p<0.001$

Table 5 Logit models for the prediction of medical school dropouts

\begin{tabular}{|c|c|c|c|}
\hline Variables & $\begin{array}{l}\text { A } \\
\text { Baseline model }\end{array}$ & $\begin{array}{l}\text { B } \\
\text { TRCP }\end{array}$ & $\begin{array}{l}\mathrm{C} \\
\text { Failure } \\
\text { ratio year } \\
1+\text { TRCP }\end{array}$ \\
\hline Gender & $\begin{array}{l}0.98 \\
(0.41)\end{array}$ & $\begin{array}{l}0.86 \\
(0.37)\end{array}$ & $\begin{array}{l}0.67 \\
(0.43)\end{array}$ \\
\hline Pre-university GPA & $\begin{array}{l}0.97 * \\
(0.02)\end{array}$ & $\begin{array}{l}0.97 \\
(0.02)\end{array}$ & $\begin{array}{l}1.04 \\
(0.04)\end{array}$ \\
\hline Age & $\begin{array}{l}1.24 * * * \\
(0.08)\end{array}$ & $\begin{array}{l}1.27 * * * \\
(0.09)\end{array}$ & $\begin{array}{l}1.35 * * * \\
(0.14)\end{array}$ \\
\hline Change of place of residence & $\begin{array}{l}1.29 \\
(0.69)\end{array}$ & $\begin{array}{l}1.13 \\
(0.68)\end{array}$ & $\begin{array}{l}0.87 \\
(0.69)\end{array}$ \\
\hline Institutional commitment & $\begin{array}{l}0.25 * * * \\
(0.13)\end{array}$ & $\begin{array}{l}0.23 * * * \\
(0.13)\end{array}$ & $\begin{array}{l}0.10 * * * \\
(0.08)\end{array}$ \\
\hline Institutional preference & $\begin{array}{l}5.91 * * * \\
(3.08)\end{array}$ & $\begin{array}{l}5.26 * * * \\
(3.07)\end{array}$ & $\begin{array}{l}11.93 * * * \\
(10.01)\end{array}$ \\
\hline Need of financial aid & $\begin{array}{l}0.24 * * * \\
(0.11)\end{array}$ & $\begin{array}{l}0.27 * * * \\
(0.13)\end{array}$ & $\begin{array}{l}0.11 * * * \\
(0.09)\end{array}$ \\
\hline Teacher ratings of class participation & & $\begin{array}{l}4.93 * * * \\
(2.05)\end{array}$ & $\begin{array}{l}3.18 * * \\
(1.83)\end{array}$ \\
\hline Year 1 failure ratio & & & $\begin{array}{l}1.17 * * * \\
(0.03)\end{array}$ \\
\hline Constant & $\begin{array}{l}1.08 \\
(4.19)\end{array}$ & $\begin{array}{l}0.16 \\
(0.65)\end{array}$ & $\begin{array}{l}0.00 * * \\
(0.00)\end{array}$ \\
\hline $\mathrm{AIC}$ & 224.14 & 210.11 & 119.35 \\
\hline $\mathrm{BIC}$ & 259.92 & 250.37 & 164.08 \\
\hline Observations & 647 & 647 & 647 \\
\hline LogLikelihood & -104.1 & -96.06 & -49.68 \\
\hline Pseudo- $R^{2}$ & 0.22 & 0.28 & 0.63 \\
\hline
\end{tabular}

TRCP teachers' ratings of class participation

Coefficients are odds-ratio. Standard errors are presented in parenthesis. ${ }^{*} p<0.05, * * p<0.01, * * * p<0.001$ for Wald tests 
university in the student's application to higher education ( $\mathrm{OR}=5.99, p<0.001)$, and not benefitting of financial aid $(\mathrm{OR}=0.24, p<0.001)$. Gender and change of residence to study at medical school were not associated with the probability of dropping out.

Adding teachers' ratings of class participation and the failure ratio in year 1 improved the baseline model's power to predict dropouts, as indicated by a slight increase in the Pseudo- $R^{2}$ and decreases in the AIC, BIC, and LogLikelihood coefficients. Students who were classified as being in the bottom-quartile of class participation were more likely to drop out $(\mathrm{OR}=4.93, p<0.001)$. The addition of failure ratio in year 1 in model $\mathrm{C}$ improved the Pseudo- $R^{2}$ from 0.28 to 0.63 , resulting in the best fitting model. According to model $\mathrm{C}$, dropout students were more likely to be older when they enrolled in medical school $(\mathrm{OR}=1.35, p<0.001)$, had lower institutional commitment levels at the beginning of the first year $(\mathrm{OR}=0.10, p<0.001)$, did not choose University of Minho as their first preference for studying in higher education $(\mathrm{OR}=11.93, p<0.001)$, did not benefit from any financial aid $(\mathrm{OR}=0.11, p<0.001)$, were rated by teachers as presenting lower levels of class participation $(\mathrm{OR}=3.18, p<0.001)$, and failed more courses in their first year in medical school $(\mathrm{OR}=1.17, p<0.001)$.

The finding that model $\mathrm{C}$ is the best fitting model is also supported by the sensitivity/ specificity results and ROC curves analysis (Table 6). Adding teachers' ratings of class participation and failure ratio in year 1 improved the model's sensitivity and positive predictive value, but had none to modest contributions for specificity and negative predictive value. Adding teachers' ratings of class participation increased the positive predictive value from $50 \%$ to $62.50 \%$, which means that the probability of dropping out for students who were identified as dropouts was $62.50 \%$. The addition of failure ratio increased the positive predictive value to $81.82 \%$. In addition, the negative predictive value or in this case the probability of not dropping out for students who in fact did not drop out was $95.46 \%$ for the model that added teachers' ratings of class participation to the baseline model. Sensitivity, which in the current study is the probability of having been identified as a dropout amongst students who actually dropped out, raised from $2.94 \%$ in Model A to $14.71 \%$ in Model B, and $52.94 \%$ in Model C. This finding means that $47 \%$ of the dropout students were not identified as dropouts. The specificity for the final model, on the other hand, indicated that the probability of a student being identified by the model as not a dropout when the student is not in fact a dropout is of $99.35 \%$. The low values of sensitivity and the high values of specificity could be due to the fact that the number of dropouts is very low when compared to the number of non-dropouts.

The hit rate, or the percentage of correctly classified cases, increases from $94.74 \%$ (Model A) to $96.91 \%$ (Model C). Finally, regarding the ROC curves, the area under the curve for Model $\mathrm{C}$ is higher than the area under the curve of Model A, with statistically

Table 6 Measures of classification of the logit models of student dropout

\begin{tabular}{lrrr}
\hline & \multicolumn{2}{l}{ Model } & \\
\cline { 2 - 4 } & A (\%) & B (\%) & C (\%) \\
\hline Sensitivity & 2.94 & 14.71 & 52.94 \\
Specificity & 99.84 & 99.51 & 99.35 \\
Positive predictive value (PPV) & 50.00 & 62.50 & 81.82 \\
Negative predictive value (NPV) & 94.88 & 95.46 & 97.44 \\
Hit rate & 94.74 & 95.05 & 96.91 \\
Area under the curve & 82.14 & 86.49 & 97.57 \\
\hline
\end{tabular}


significant differences between both models, which suggests a higher predictive ability of Model C to identify dropouts. The ROC curves of these two models are presented in Fig. 1. The area under the curve for the final model shows that this model presents very good discriminating ability.

\section{Discussion}

The primary goal of this study was to study the relevance of including teachers' ratings of class participation as a predictor of dropouts from medical school. The study was underpinned by theoretical models of student persistence in higher education (Astin 1984; Tinto 1993), which led us to the hypothesis that less class participation would reflect lower levels of student involvement and engagement. We explored the incremental predictive power of aggregate scores of multiple observations of student class participation by different teachers in the prediction of year 1 student dropouts in one medical school, over student entry characteristics and academic underperformance. We found that adding class participation to a baseline model which included students' pre-entry characteristics improved, albeit modestly, the ability to accurately predict dropouts. Students who were consistently rated by their teachers of presenting fewer desirable class participation behaviors throughout the first year had an increased probability of dropping out.

The fact that an aggregate score of student participation in class collected systematically in a simple scale by multiple teachers can be useful in the process of identifying potential dropouts is, to our best knowledge, an original contribution. Prior studies had already shown the potential of using tutors' information to identify struggling students (Wijnia et al. 2014; O'Neill et al. 2016; Wijnia et al. 2016), but in these studies the tutor/ students ratio was low and, therefore, there were more frequent contacts with the students. Our study provides other contextual circumstances. There were multiple raters of class participation who were content-expert teachers and who interacted with students in small and

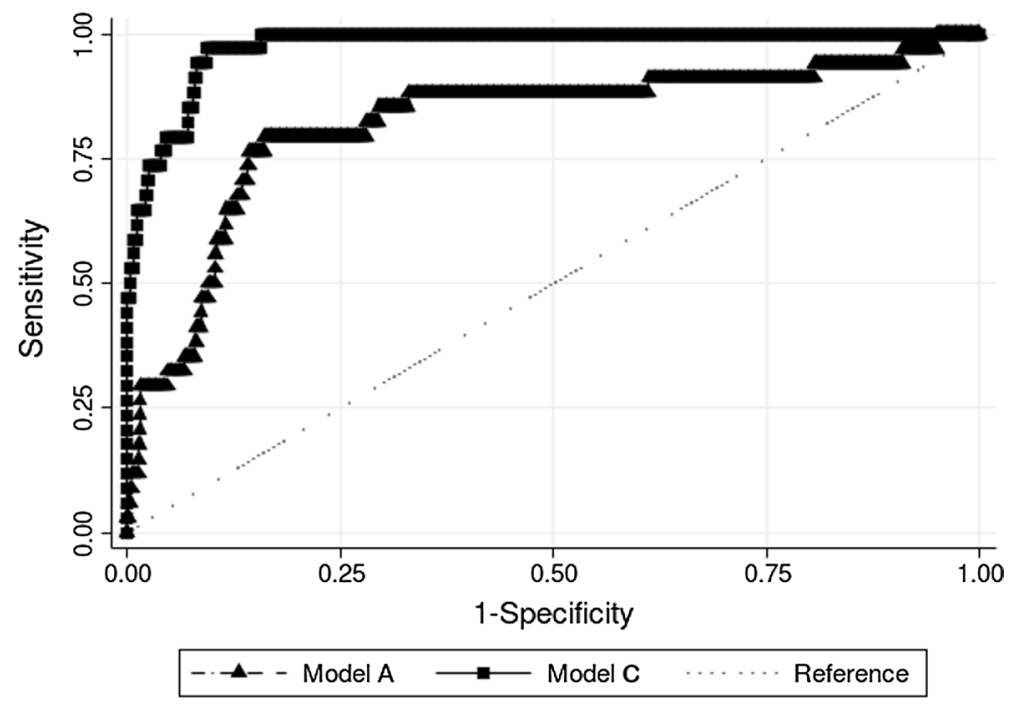

Fig. 1 ROC curves for Model A and Model C 
large classes, across many weeks in year 1 courses. The variability in behavior across time and contexts accounted for in ratings of class participation in the current study has the potential of canceling single-rater bias and including students' different approaches to different courses.

The scores of class participation, including observable signs of initiative and active participation in discussions, were considered in the current study as a proxy for involvement (Astin 1984) and engagement (Hu and Kuh 2002; Kuh et al. 2008; Kahu 2013; Tinto 2012). Our study aimed to provide a measure of the behavioral meaning of involvement, as presented by Astin (1984), surpassing the bias of self-report data. In this study's context, the investment that students placed in class activities, measured by their teachers in class, accounted for $10 \%$ of their final marks and therefore to academic success. Despite contributing modestly to an increase in the predictive power of identifying dropouts, participation deemed to be a significant variable for students' persistence. Even though the inclusion of course failure resulted in higher explanatory power than participation in class, ratings of class participation may be advantageous to anticipate dropout identification, as those can be collected prior to course failure. Furthermore, while we conceptualized class participation as a predictor of students' persistence versus dropout, it may be purposeful to look at the quality of engagement in the classroom as an educational outcome or phenomenon in its own right. Future research should look at the conditions associated with participation and how teachers enrich and stimulate students' class participation.

This study was possible because the assessment program in the school is coherent across courses and determines that student participation must be registered. In practice, all courses are integrated and involve multiple teachers, who have electronic access to student photographs and a platform to record participation scores. The score is global, which increases teachers' adherence to evaluation and the feasibility of the scoring process. The scoring of participation is now an accepted daily practice by teachers, largely facilitated by the perceived ease of the use of the online platform to mark class participation. From an educational management standpoint, this means that investing in tools that help teachers provide timely feedback to students, such as the one used in the present study, can potentially help medical schools identify struggling students and retain them through remediation interventions. Such continuous assessment practices are beneficial in the way they place a focus on academic success as an outcome of day-to-day behaviors of engagement, providing additional information for formal evaluations of knowledge and skills.

Consistent with prior research in medical education (Hojat et al. 1997; Yates 2011, 2012), we found that failing academically was related to higher chances of dropping out. In our study, adding the failure ratio of courses in year 1 significantly improved the probability of correctly identifying dropouts, over the baseline model and the addition of class participation. Students who are successful in their application to medical school, generally have a consistent record of excellent performance in secondary education and most likely had not failed courses before. Such an experience of failure in medical school clashes with students' constructed academic self-concept, which can result in frustration and disappointment and a decrease in self-confidence and motivation. Moreover, academic failure can indicate a lack of key study skills for the type of academic load and learning expectations in medical school. Such students would benefit from educational interventions for remediation, preventing future outcomes of attrition.

In the current study, class participation and failure ratio in year 1 added predictive power to a baseline model, which included students' characteristics. We found that higher probabilities of dropping out were associated with lower pre-university GPAs, older ages, a lower institutional commitment at the beginning of the first year, a lower preference for 
the university in the student's application to higher education, and not benefitting of financial aid, while gender and change of residence to study at medical school were not associated with the probability of dropping out. In general, these results are consistent with prior research that has described the contribution of prior academic tracks and demographics to identify struggling students (Simpson and Budd 1996; Hojat et al. 1997; Arulampalam et al. 2004; Yates and James 2007; Yates 2011, 2012; Maher et al. 2013). Although findings regarding the importance of demographics for dropping out are inconsistent (O'Neill et al. 2016), probably due to the nature of samples and differences in medical schools and programs, our study confirms the relevance of taking entry characteristics into account when studying student dropout. Therefore, the current study adds to the empirical support of the theoretical models presented by Astin (1984) and Tinto (1993), which both pay special attention to students' "inputs" or pre-entry attributes, respectively, as predictors of involvement and commitment.

\section{Limitations}

There are several limitations to the current study. First, the demographic homogeneity of our sample conditions the international generalization of our findings. Students were mostly Caucasian and high school entrants (with 17-18 years old at entry in medical school), with few adult-life responsibilities (e.g., having financial debt, a job, or taking care of dependents). Neither family-work balance nor social and cultural acculturation was a significant issue for most participants, and therefore generalization to institutions with different population profiles must be made with caution. Second, this study was conducted in a single medical school and may not be generalizable to other schools with different curricular arrangements and teaching approaches. Third, the current study was conducted in a high-school entry medical education setting, which limits generalization to graduate-entry medical education. The participants in our study were exposed to a combination of large group lectures, small group, and clinical experiences where the consistent participation of all students can be challenging due to logistics: students are more willing to participate, less anxious about participating, and less likely to "hide" in smaller classes than in larger classes (Rocca 2010). In graduate programs, students have a closer and more individualized relationship with teachers, compared to undergraduate education. In addition, graduate programs are more research-oriented and specialized than undergraduate programs, and therefore students are more likely to perceive a greater alignment between the curriculum and their personal interests and motivations, which can increase the motivation for participation. Due to the nature of such differences, our findings are not generalizable to students admitted to graduate medical education. The fourth limitation of our study is set on the fact that participation required teachers' judgment, which can carry subjectivity and therefore variability in scoring. Fifth, we did not account for variance across cohorts regarding faculty composition and teaching experience. Sixth, because this study relied on students' academic files and was retrospective in nature, we could not collect information regarding students' motivations at the moment they dropped out. Such a limitation prevented us from differentiating between dropouts due to struggling in medical school and "opt-outs" due to following preferred placements in other universities or courses. Finally, we did not control for macro-level influences that might have influenced students' decisions to leave in a particular cohort, regarding fluctuations in the global economy, in national GPAs, and in the amount of financial aid provided by the university and government to students in need of support. 


\section{Future studies and practical implications}

Future studies should include multi-institutional samples to clarify generalization issues. In addition, future studies on the influence of class participation on dropout and academic involvement should account for differences between students, based on their academic track (undergraduate or graduate), the curriculum, and the learning environment, including variables such as class size or the use of active pedagogies. Regarding the measurement of participation as a tool for the identification of at-risk students, future studies can look into the variability of participation scoring in faculty, across different courses and types of lectures, and throughout the academic year. We collected measures of teachers' subjective evaluations of participation, but not of which environment each teacher created for challenging students to think critically and creatively and solve problems in the classroom. Therefore, we suggest future studies on class participation to explore the interactions between the student and the teacher and how the student makes use of the environmental resources to actively engage in the classroom. Future research may also attempt to include peers' reports on participation, as this study proved that moving beyond self-reports may provide relevant information for identifying at-risk students. Despite the relevance of year 1 for students' transition and integration in medical school, future studies can also be extended to the following years in medical training and graduate-entry student populations. In addition, the meaning of class participation for students should also be explored, namely through qualitative inquiry. In the current study, participation accounted for $10 \%$ of students' grades, which can be seen as an extrinsic motivator for engagement in the classroom. Since students were informed that participation contributed to academic performance, they may have made an increased effort to participate in class discussions. Future studies can explore if participation is a predictor of dropping out in situations where participation is registered but is not included in students' marks (e.g., in classes where students gain extra credit for participation). Some questions that can be addressed in future research are what motivates students to participate in class, what prevents students from participating, and how participating in class transfers to individual learning. Regarding the reasons underlying dropout, it would be relevant to develop a system of registering motivations to drop out, based on structured interviews and follow-ups. Finally, the present study may be furthered through an exploration of the relations between the explanatory variables we identified. For instance, it would be interesting looking into the relations between institutional commitment and participation, as it is expected that students who wish to pursue their training at the university they enrolled in will more likely invest in interpersonal relations with peers and faculty, which will facilitate participation in the classroom.

The first practical implication of this study is that it is beneficial to stimulate students' participation in the classroom in order to prevent dropping out. Tinto (1993) and Astin (1993) provide theoretical foundations on which to build classrooms that foster students' participation. According to Astin (1993), frequent student-faculty and student-student interactions, the amount of time studying, tutoring, cooperative learning, and encouraging students to give class presentations all positively impact student involvement and development. Tinto $(1993,2012)$ added that the communities in which students participate in higher education can be a means to improve academic and social integration, contributing to student retention. The classroom is one of the most critical communities for students' integration, learning, and development. Through participation, students feel a sense of academic accomplishment and belonging, as they build meaningful connections with their teachers and peers. Therefore, instructional design should employ pedagogies of 
engagement in the classroom, such as cooperative and problem-based learning, that require students to be more active, collaborate, and take responsibility not only for their own learning, but also for the learning of their peers. Teachers can provide conditions that increase participation, such as resorting to class discussions, breaking students into smaller groups in class and organizing group activities, using audience response systems such as clickers, calling students by their names, and moving around in the classroom so that students feel closer to them and therefore more willing to participate (Rocca 2010). The increased contact with students resulting from such strategies helps teachers gain an awareness of students' academic and personal needs, effectively communicate clear and high expectations for learning, provide prompt feedback, and respect diverse talent and ways of learning, therefore reinforcing students' active participation.

The second practical implication of the current study is that there is a need to develop valid and reliable measures of class participation. The assessment of classroom participation should encourage students to participate in class discussion and adequately prepare for classes. However, students need to clearly understand what are the expectations for participation and how participation is aligned with learning outcomes. Effective assessment tools should include standards for distinguished, proficient, basic, and unacceptable participation. Good practice in the assessment of class participation includes establishing clear and simple criteria by which participation is marked, differentiating attendance from participation, communicating clearly how can students prepare for participation in class, providing timely feedback on the quality of participation, and letting students have real-time access to their marks of class participation, in order to foster self-regulation of behavior and learning. Teachers need to ensure fairness in the evaluation of participation, meaning that not only they use the established marking criteria in a systematic and consistent way, but also that they are trained to facilitate equitable participation for all students and do not discriminate against students who are shy or low in self-confidence, fear peer disapproval, women, students with a disability, or those from different cultural backgrounds (Weaver and Qi 2005). In addition, the active involvement of students in the definition of the marking criteria and in self-assessment can facilitate self-monitoring in participation and fairness in its assessment (Rocca 2010).

A final practical implication of this study is the importance of conducting longitudinal assessments of students, with various measurement points and different types of data, starting at students' admission in medical school. From an educational perspective, collecting measures of class participation can be seen as a formative opportunity, in order to help students do a better job of learning. These continuous streams of information about the way students are engaged in the classroom have the potential to early inform students and teachers about the quality of learning and potentially identify students at-risk of dropping out, before students fail academically, which is generally the first sign of trouble in medical school (Yates 2011, 2012). Although academic performance, in the form of the failure ratio of courses in year 1, significantly enhanced the model's predictive ability, when students face such academic failure the school can no longer take preventive measures. On the other hand, when student services and administration flag students with the early identified risk factors and low participation scores, remediation can take place to prevent lack of commitment, involvement, and low performance. Therefore, we suggest adding low participation in class as an additional red flag to the "toolkit" to identify struggling students (Yates 2011).

Acknowledgements The authors would like to express their gratitude to all faculty members of the School of Medicine for their permanent commitment to the process of assessment of student participation. The 
authors also thank the medical school deanery and all students for their support and commitment to the ongoing Minho Longitudinal Education Study (MILES Study) that originated the data for this study.

\section{References}

Adam, J., Bore, M., McKendree, J., Munro, D., \& Powis, D. (2012). Can personal qualities of medical students predict in-course examination success and professional behaviour? An exploratory prospective cohort study. BMC Medical Education, 12, 69. https://doi.org/10.1186/1472-6920-12-69.

Arulampalam, W., Naylor, R., \& Smith, J. (2004). Factors affecting the probability of first year medical student dropout in the UK: A logistic analysis for the intake cohorts of 1980-92. Medical Education, 38(5), 492-503. https://doi.org/10.1046/j.1365-2929.2004.01815.x.

Arulampalam, W., Naylor, R. A., \& Smith, J. P. (2007). Dropping out of medical school in the UK: Explaining the changes over ten years. Medical Education, 41(4), 385-394. https://doi.org/10.111 1/j.1365-2929.2007.02710.x.

Astin, A. W. (1984). Student involvement: A developmental theory for higher education. Journal of College Student Personnel, 25(4), 297-308.

Astin, A. W. (1993). What matters in college: Four critical years revisited. San Francisco, CA: Jossey-Bass.

Bösner, S., Pickert, J., \& Stibane, T. (2015). Teaching differential diagnosis in primary care using an inverted classroom approach: Student satisfaction and gain in skills and knowledge. BMC Medical Education, 15, 63. https://doi.org/10.1186/s12909-015-0346-x.

Carini, R. M., Kuh, G. D., \& Klein, S. P. (2006). Student engagement and student learning: Testing the linkages. Research in Higher Education, 47(1), 1-32. https://doi.org/10.1007/s11162-005-8150-9.

Cohen, J. (1988). Statistical power analysis for the behavioral sciences (2nd ed.). Hillsdale: LEA.

Compton, M. T., Carrera, J., \& Frank, E. (2008). Stress and depressive symptoms/dysphoria among US medical students: Results from a large, nationally representative survey. Journal of Nervous and Mental Disease, 196(12), 891-897. https://doi.org/10.1097/nmd.0b013e3181924d03.

Duffy, R. D., Manuel, R. S., Borges, N. J., \& Bott, E. M. (2011). Calling, vocational development, and wellbeing: A longitudinal study of medical students. Journal of Vocational Behavior, 79(2), 361-366. https ://doi.org/10.1016/j.jvb.2011.03.023.

Dyrbye, L. N., Thomas, M. R., Power, D. V., Durning, S., Moutier, C., Massie, F. S., Jr., et al. (2010). Burnout and serious thoughts of dropping out of medical school: A multi-institutional study. Academic Medicine, 85(1), 94-102. https://doi.org/10.1097/acm.0b013e3181c46aad.

Dyrbye, L. N., Thomas, M. R., \& Shanafelt, T. D. (2006). Systematic review of depression, anxiety, and other indicators of psychological distress among U. S. and Canadian medical students. Academic Medicine, 81(4), 354-373.

Fonseca, M., Dias, D., Sá, C., \& Amaral, A. (2014). Waves of (dis)satisfaction: Effects of the numerus clausus system in Portugal. European Journal of Education, 49(1), 144-158. https://doi.org/10.1111/ ejed.12042.

Frellsen, S., Baker, E. A., Papp, K. K., \& Durning, S. J. (2008). Medical school policies regarding struggling students during the internal medicine clerkships: Results of a national survey. Academic Medicine, 83(9), 876-881. https://doi.org/10.1097/acm.0b013e318181da98.

Garrud, P., \& Yates, J. (2012). Profiling strugglers in a graduate-entry medicine course at Nottingham: A retrospective case study. BMC Medical Education, 12, 124. https://doi.org/10.1186/1472-6920-12-124.

Goldberg, L. R., Bell, E., King, C., O’Mara, C., McInerney, F., Robinson, A., et al. (2015). Relationship between participants' level of education and engagement in their completion of the Understanding Dementia Massive Open Online Course. BMC Medical Education, 15, 60. https://doi.org/10.1186/ s12909-015-0344-z.

Hojat, M., Gonnella, J. S., Erdmann, J. B., \& Veloski, J. J. (1997). The fate of medical students with different levels of knowledge: Are basic medical sciences relevant to physician competence? Advances in Health Sciences Education, 1(3), 179-196.

Hu, S., \& Kuh, G. D. (2002). Being (dis)engaged in educationally purposeful activities: The influences of student and institutional characteristics. Research in Higher Education, 43(5), 555-575.

Jones, R. F., \& Korn, D. (1997). On the cost of educating a medical student. Academic Medicine, 72(3), 200-210.

Kahu, E. R. (2013). Framing student engagement in higher education. Studies in Higher Education, 38(5), 758-773. https://doi.org/10.1080/03075079.2011.598505.

Kaufman, D. M., \& Hansell, M. M. (1997). Can non-expert PBL tutors predict their students'achievement? An exploratory study. Academic Medicine, 72(Suppl. 1), S16-S18. 
Krause, K.-L., \& Coates, H. (2008). Students' engagement in first-year university. Assessment and Evaluation in Higher Education, 33(5), 493-505. https://doi.org/10.1080/02602930701698892.

Kuh, G. D. (2003). What we're learning about student engagement from NSSE. Change, 35(2), 24-32. https ://doi.org/10.1080/00091380309604090.

Kuh, G. D., Cruce, T. M., Shoup, R., Kinzie, J., \& Gonyea, R. M. (2008). Unmasking the effects of student engagement on first-year college grades and persistence. Journal of Higher Education, 79(5), 540563. https://doi.org/10.1353/jhe.0.0019.

Lameris, A. L., Hoenderop, J. G. J., Bindels, R. J. M., \& Eijsvogels, T. M. H. (2015). The impact of formative testing on study behavior and study performance of (bio)medical students: A smartphone application intervention study. BMC Medical Education, 15, 72. https://doi.org/10.1186/s12909-015-0351-0.

Liu, R., Carrese, J., Colbert-Getz, J., Geller, G., \& Shochet, R. (2015). “Am I cut for this?” Understanding the experience of doubt among first-year medical students. Medical Teacher, 37(12), 1083-1089. https ://doi.org/10.3109/0142159x.2014.970987.

Maher, B. M., Hynes, H., Sweeney, C., Khashan, A. S., O’Rourke, M., Doran, K., et al. (2013). Medical school attrition-Beyond the statistics. A ten year retrospective study. BMC Medical Education, 13, 13. https://doi.org/10.1186/1472-6920-13-13.

Mørcke, A. M., O’Neill, L., Kjeldsen, I. T., \& Eika, B. E. (2012). Selected determinants may account for dropout risks among medical students. Danish Medical Journal, 59(9), A4493.

O’Brien, B., Cooke, M., \& Irby, D. M. (2007). Perceptions and attributions of third-year student struggles in clerkships: Do students and clerkship directors agree? Academic Medicine, 82(10), 970-978. https:// doi.org/10.1097/acm.0b013e31814a4fd5.

O’Neill, L. D., Mørcke, A. M., \& Eika, B. (2016). The validity of student tutors' judgments in early detection of struggling in medical school. A prospective cohort study. Advances in Health Sciences Education, 21(5), 1061-1079. https://doi.org/10.1007/s10459-016-9677-6.

O’Neill, L. D., Wallstedt, B., Eika, B., \& Hartvigsen., J. (2011). Factors associated with dropout in medical education: A literature review. Medical Education, 45(5), 440-454. https://doi.org/10.111 1/j.1365-2923.2010.03898.x.

Papadakis, M. A., Hodgson, C. S., Theherani, A., \& Kohatsu, N. D. (2004). Unprofessional behavior in medical school is associated with subsequent disciplinary action by a state medical board. Academic Medicine, 79(3), 244-249.

Robbins, S. B., Lauver, K., Le, H., David, D., Langley, R., \& Carlstom, A. (2004). Do psychosocial and study skills factors predict college outcomes? A meta-analysis. Psychological Bulletin, 130(2), 261288. https://doi.org/10.1037/0033-2909.130.2.261.

Rocca, K. A. (2010). Student participation in the college classroom: An extended multidisciplinary literature review. Communication Education, 59(2), 185-213. https://doi.org/10.1080/03634520903505936.

Sandars, J., Patel, R., Steele, H., \& McAreavey, M. (2014). Developmental student support in undergraduate medical education: AMEE Guide No. 92. Medical Teacher, 36(12), 1015-1026. https://doi. org/10.3109/0142159x.2014.917166.

Simpson, K. H., \& Budd, K. (1996). Medical student attrition: A 10-year survey in one medical school. Medical Education, 30(3), 172-178. https://doi.org/10.1111/j.1365-2923.1996.tb00739.x.

Svanum, S., \& Bigatti, S. M. (2009). Academic course engagement during one semester forecasts college success: Engaged students are more likely to earn a degree, do it faster, and do it better. Journal of College Student Development, 50(1), 120-132.

Tinto, V. (1993). Leaving college: Rethinking the causes and cures of student attrition (2nd ed.). Chicago: University of Chicago Press.

Tinto, V. (2012). Enhancing student success: Taking the classroom success seriously. The International Journal of the First Year in Higher Education, 3(1), 1-8. https://doi.org/10.5204/intjfyhe.v3i1.119.

Tyssen, R., Dolatowski, F. C., Røvik, J. O., Thorkildsen, R. F., Ekeberg, O., Hem, E., et al. (2007). Personality traits and types predict medical school stress: A six-year longitudinal and nationwide study. Medical Education, 41(8), 781-787. https://doi.org/10.1111/j.1365-2923.2007.02802.x.

Urlings-Strop, L. C., Stijnen, T., Themmen, A. P., \& Splinter, T. A. (2009). Selection of medical students: A controlled experiment. Medical Education, 43(2), 175-183. https://doi.org/10.111 1/j.1365-2923.2008.03267.x.

Ward, A. M., Kamien, M., \& Lopez, D. G. (2004). Medical career choice and practice location: Early factors predicting course completion, career choice and practice location. Medical Education, 38(3), 239248. https://doi.org/10.1046/j.1365-2923.2004.01762.x.

Weaver, R. R., \& Qi, J. (2005). Classroom organization and participation: College students' perceptions. The Journal of Higher Education, 76(5), 570-601.

Whitfield, C. F., \& Xie, S. X. (2002). Correlation of problem-based learning facilitators' scores with student performance on written exams. Advances in Health Sciences Education, 7(1), 41-51. 
Wijnia, L., Loyens, S. M. M., Derous, E., Koendjie, N. S., \& Schmidt, H. G. (2014). Predicting educational success and attrition in problem-based learning: Do first impressions count? Studies in Higher Education, 39(6), 967-982. https://doi.org/10.1080/03075079.2012.754856.

Wijnia, L., Loyens, S. M. M., Derous, E., \& Schmidt, H. G. (2016). University teacher judgments in problem-based learning: Their accuracy and reasoning. Teaching and Teacher Education, 59, 203-212. https://doi.org/10.1016/j.tate.2016.06.005.

Yates, J. (2011). Development of a "toolkit" to identify medical students at risk of failure to thrive on the course: An explorative retrospective case study. BMC Medical Education, 11, 95. https://doi. org/10.1186/1472-6920-11-95.

Yates, J. (2012). When did they leave, and why? A restrospective case study of attrition on the Nottingham undergraduate medical course. BMC Medical Education, 12, 43. https://doi. org/10.1186/1472-6920-12-43.

Yates, J., \& James, D. (2006). Predicting the "strugglers"': A case-control study of students at Nottingham University Medical School. British Medical Journal, 332(7548), 1009-1013. https://doi.org/10.1136/ bmj.38730.678310.63.

Yates, J., \& James, D. (2007). Risk factors for poor performance on the undergraduate medical course: Cohort study at Nottingham University. Medical Education, 41(1), 65-73. https://doi.org/10.111 1/j.1365-2929.2006.02648.x.

Yates, J., \& James, D. (2010). Risk factors at medical school for subsequent professional misconducts: Multicentre retrospective case-control study. BMJ, 340, c2040. https://doi.org/10.1136/bmj.c2040. 